\title{
«VOLVER A UN ORIGEN DESNUDO». REFRACCIONES DE INCOMPLETITUD ONTOLÓGICA EN LA OBRA PICTÓRICA de RAMÓN GAYA
}

\author{
Marius Christian Bomholt \\ Universidad Complutense
}

Instituto Universitario de Investigación Ortega y Gasset

\section{RESUMEN:}

Este análisis de los escritos y la obra plástica de Ramón Gaya se divide en dos partes principales. Se comienza con una reflexión sobre la conocida aversión del murciano a la crítica artística, a lo largo de la cual se descubre una estrategia epistemológica dual como elemento central y estructurante de su pensamiento. Tal dualidad deja su impronta también sobre el concepto de arte de Gaya, un arte que, de siempre, se comprometió con la búsqueda de una verdad pictórica más allá de las apariencias, según lo ha constatado -apréciese la ironía- un buen número de sus intérpretes. Inspirado en las aportaciones de ese conjunto de críticos, el presente ensayo propone un nuevo acceso a las creaciones pictóricas de Gaya: entender las mismas como expresión y reflejo de la incompletitud ontológica de lo existente, según la desarrolló el pensador esloveno Slavoj Žižek.

\section{PALABRAS CLAVE:}

Ramón Gaya, pintura, siglo xx, Slavoj Žižek, incompletitud ontológica.

\begin{abstract}
:
The present analysis of Ramón Gaya's writings and visual art is divided into two main parts. It begins with a reflection on the famously hostile attitude the Spanish painter displayed toward art criticism, revealing a strategy of epistemological duality as a key structuring element of his thought. This duality has also left its mark on Gaya's concept of art, an art that was always committed to discovering a pictorial truth beyond mere appearances, as, somewhat ironically, many of his commentators have pointed out. Drawing on these previous explorations as a source of inspiration, the present essay proposes a new access to Gaya's works: understanding them, in accordance with Slovenian philosopher Slavoj Žižek's theories, as a reflection and an expression of the fundamental ontological incompleteness of existence itself.
\end{abstract}

\section{KEYWORDS:}

Ramón Gaya, painting, $20^{\text {th }}$ century, Slavoj Žižek, ontological incompleteness. 


\section{Proemio: crítica artística, malgré tout}

Cuando uno se propone investigar y escribir en torno a la obra pictórica de Ramón Gaya -como lo hacemos nosotros, aquí y ahora, y como lo hará a buen seguro la mayor parte de los contribuidores a este número de Monteagudo dedicado al gran pintor murciano-, conviene tener presente el carácter, si no abiertamente paradójico, por lo menos fundamentalmente irónico de esa empresa, puesto que, a lo largo de su extensa trayectoria, las ocasiones en las que el pintor encontró palabras amigables para la crítica artística son contadas. Y en verdad, no se trataba sólo de una falta de inclinación afable: podría decirse incluso que Gaya detestaba la crítica, un sentimiento de inquina presente tanto en sus textos más tempranos -destaca al respecto El sentimiento de la pintura, en el que habla de aquel «error inicial», del que caen víctimas los «cultivadores profesionales: los historiadores, los críticos, los estetas» (2010a: 31) - como en los escritos maduros (2010f: 929-953). Somos conscientes, naturalmente, de que la aversión del creador no invalida el esfuerzo del intérprete. Es más: quien crea, se expone, $\mathrm{y}$, aunque en definitiva no obtuvieron nunca el favor del murciano, la crítica y el estudio de las artes, aparte de enriquecer los discursos teóricos, cumplen una serie de importantes funciones sociales. Todo ello le importaba bien poco a Gaya: resulta fascinantemente extraño ese rechazo visceral a los críticos que exhibió con tesón y persistencia. Su motivo último es insondable, evidentemente, pero la obra escrita del pintor, esa amplia complementación de su trabajo sobre el lienzo, nos puede deparar una serie de pistas para ir esgrimiendo algunos de los aspectos más significativos. Así, por nuestra parte, encontramos en esa aversión atisbos de una búsqueda más primigenia y global, de una pulsión fundamental que atraviesa la ceuvre del pintor: la de descubrir una verdad pictórica, la de buscar -y encontrar- la 'sustancia' o la 'esencia' de la pintura', la de apreciar la creación de la manera más inmediata, atemporal y espontánea posible; tareas todas ellas de las que, según Gaya, los críticos no son capaces². Más que servirnos aquí como mera anécdota, referida tal vez a modo de captatio benevolentiae, un breve examen de la curiosa ojeriza de Gaya hacia los jueces del arte resulta, de hecho, muy iluminador con respecto a su concepto del arte y de la pintura, al tiempo que constituye, claro está, un buen gancho para comenzar un artículo sobre su arte.

Cabe señalar de entrada, por supuesto, que aquellas partes de un pensamiento que tan diáfanamente se vinculan con el lado afectivo de la psique de su autor siempre se presentan espinosas. Es difícil saber a ciencia cierta, al fin y al cabo, cuáles son los motivos reales que subyacen en una postura tan visiblemente emocional como la

\footnotetext{
${ }^{1}$ Dos términos de los más frecuentes en todo el corpus gayesco.

${ }^{2}$ Véase al respecto por ejemplo Gaya (2010a: 32-34).
} 
"Volver a un origen desnudo". Refracciones de incompletitud ontológica en la obra pictórica de ...

de Gaya frente a la crítica. Entramos, por tanto, en terreno de especulación, aunque estamos convencidos de que las deducciones nuestras, más que conjeturas airosas e infundadas, se dejan entrever con relativa claridad en las claves proporcionadas por Gaya en sus escritos. Decimos todo esto, porque en verdad el curioso dato de la malquerencia de los críticos podría entenderse asimismo, simple y llanamente, como parte de la idiosincrasia de la persona histórica Ramón Gaya, como poco más que un capricho, arbitrario e inmotivado, una peculiaridad como cualquier otra. Si decidimos, no obstante, reparar un momento más sobre él, se le descubre también una lectura próxima al comentario social, un enfoque que traduce el enojo del murciano con los jueces de su métier a una observación más abstracta sobre la prevalencia indebida de los no-creadores -intelectuales, sobrecultivados y alienados hasta el punto de que no son capaces de disfrutar el arte de manera 'natural'- en un ámbito principalmente constituido por los que crean y las obras que producen (2010f: 939-945). Esa distinción entre creadores y no-creadores (los «gustadores, amadores, consumidores» (2010f: 933), al decir de Gaya), la desarrolló con gran detalle (y, algunos dirían, furor) en su último texto, el ensayo Naturalidad del arte (y artificialidad de la crítica) del año 1996.

A algunos conocedores del arte de Gaya, las inferencias biográficas en este punto les resultarán evidentes: las contaminaciones entre vida y obra, vida y pensamiento de un creador - tan difíciles de rastrear y averiguar con certeza en la mayoría de los casos, a pesar de la suma facilidad con la que se producen sin excepciónaquí parecen visibles, inevitables. Se ha convertido en un dato clave, tanto en las aproximaciones biográficas como en el discurso artístico e historiográfico sobre su figura y obra, el desencanto que Gaya experimentó en su primer viaje a París y, en concomitancia con ello, su rechazo al arte de las vanguardias 'clásicas', en aquel momento concentradas con práctica exclusividad en la capital francesa (Moreno Aguirre, 2018: 27-31). Nosotros, por más que les tengamos una estima escasa a los análisis demasiado centrados en las menudencias de una vida ajena -en una palabra: biografistas-, no podemos negar la actitud discordante de Gaya. Está ahí, confirmada por él mismo, tanto en las sugerentes entrevistas que se publicaron en varios diarios españoles ${ }^{3}$ como también, con mayor proximidad temporal a las vivencias francesas, en la temprana carta que dirigió al amigo Juan Guerrero Ruiz, fechada el 19 de mayo de 1928: «Tiene usted una idea falsa de París», le comenta, porque «en París no se

\footnotetext{
${ }^{3}$ Véanse por ejemplo la de María José Muñoz Peirats para Las Provincias, publicada en 1984, o el texto de Vicente Molina Foix, de índole más híbrida, publicado en El País en 1996. En la primera, Gaya comenta sobre el arte de vanguardia que conoció en el viaje a la capital francesa: «[T]odas esas formas que me habían fascinado en la distancia, cuando llegué a París y las vi directamente, cuando vi los Braque, los Matisse, los Rouault..., directamente, me desilusionaron muchísimo, porque les vi algo muy endeble; me pareció que no estaban hechos dentro de la pintura» (2007: 246).
} 
paga el mejor cuadro, se paga la mejor firma [...]. En París se vende la pintura por metros; como los solares por construir» (2000: 107).

La queja es breve, pero el desengaño que en ella se percibe es profundo. Gaya se ve repelido por el mercantilismo inherente a la actividad artística de París, por las señoras patricias que adquieren pinturas con «gesto de comprar alfombras» (2000: 107), pero también por esa suerte de star system implementado en las esferas creativas de la capital, donde el nombre del autor vale más que la calidad estética de la obra. Críticos, historiadores y estetas -la temprana tríada de los no-creadores identificada por Gaya- son, todos ellos, engranajes imprescindibles en aquella ingente maquinaria de producción artística, mejor descrita, sin duda alguna, con el término alemán de Kunstbetrieb. No es del todo improbable, por consiguiente, que el rechazo hacia la crítica artística, que acompañó al murciano durante prácticamente el total de su trayectoria y que a veces formuló con una dureza ya rayana en la acrimonia, pudo tener aquellas tempranas desventuras como punto de origen.

Ahora bien, aun habiendo comprobado la congoja del murciano en París en sus recuerdos, pronto nos damos cuenta de que, si bien así se explica el origen de sus inclinaciones adversas hacia el sector de la crítica, poco nos revela sobre su concepto de arte y creación -como es sabido, prefería con creces el término último (2007: 75)-, poco aclara en lo teórico sus reflexiones menos afectivas, más meditadas y pausadas sobre la inferioridad que percibe en los críticos, sobre todo cuando se enfrentan a los creadores 'verdaderos' (poca o ninguna duda cabe de que Gaya, a priori, se incluyó en ese segundo colectivo). A la vez, al menos en nuestra estimación, parece que el peso de aquel desaliento parisino, acontecido durante los años más jóvenes de Gaya, ha sido un tanto exagerado por algunos de sus comentaristas, a tal punto que se ha convertido en una suerte de topos - muchas veces reproducido, aunque de poca sustancia- en la actualidad. Consideremos el ejemplo del Museo Ramón Gaya, que justo en el momento de redacción de este ensayo celebra a su homenajeado no sólo con la excelente colección permanente, sino también en una muestra temporal que reúne una serie de otras piezas, no siempre expuestas, pero igualmente de gran atractivo estético. Las ha agrupado según cuatro etapas vitales del pintor, siendo la primera, 'juventud', la que recoge, supuestamente, testimonios artísticos de su «tímido acercamiento a las vanguardias» y su «posterior desencanto» ${ }^{4}$. Lástima que las obras escogidas para la misma, en nuestra perspectiva, no sean reflejo de aquello que pretenden mostrar. Se trata, antes bien, de la reproducción de lo que viene a ser un lugar común sobre la vida del pintor, perpetuado, en este caso específico, sin justificación suficiente en la muestra.

\footnotetext{
${ }^{4}$ Texto copiado del vinilo de sala en el Museo Ramón Gaya.
} 
"Volver a un origen desnudo". Refracciones de incompletitud ontológica en la obra pictórica de ...

¿Cómo comprender, entonces, la aversión del murciano contra la crítica artística en términos más teóricos? La lectura de ese curioso fenómeno que proponemos nosotros se inserta en la figura de un pensamiento constitutivamente dual detectable en un nutrido número de textos de Gaya. No nos referimos a una pugna dialéctica entre dos fuerzas antagónicas o a un juego de conceptos o categorías dicotómicas, sino, antes bien, a la doble vía epistemológica que Gaya emplea a menudo para dar cuerpo a sus ideas más personales. Meditando en torno a un acto, un término o un fenómeno, que, si bien las distintas maneras de entender el mismo se suelen diferenciar en algunos puntos, por lo común no admite lecturas diametralmente opuestas, Gaya hace precisamente eso: contrapone una definición sencilla y consuetudinaria a otra nueva, compleja, personal y del todo adversa a la primera en términos semánticos. Pocos momentos en la obra del murciano alumbran esa técnica dual con mayor claridad que su reflexión sobre la diferencia que percibe entre 'pensar' y 'tener pensamiento', desplegada en el comienzo del breve texto «El fruto original»:

Como se sabe, pensar, tener y ejercer la muy humana, demasiado humana facultad o capacidad de pensar, es algo muy distinto a tener... Pensamiento. Tan distinto, que es casi lo contrario, pues para pensar sólo se necesita disponer de una buena maquinaria pensante -que no es mal regalo-, mientras que tener Pensamiento, ser Pensamiento, sólo se puede tener y ser... sin pensar, involuntariamente, es decir, como algo recibido, pero no ya recibido como un simple regalo útil, sino como un alto don valioso, y... no demasiado humano (2010e: 855-856).

Resulta cuando menos curioso el modo en que Gaya decide comenzar el pasaje citado: con su «como se sabe» alega que la diferencia que traza entre 'pensar' y 'tener Pensamiento' es un hecho consabido, mientras que el uso habitual sugeriría que se trata de dos expresiones sinónimas (si bien 'tener pensamiento', así a secas, queda poco idiomático). Señalar esa supuesta notoriedad de su distinción, sin embargo, no basta para enmascarar el hecho de que se trata de una teorización altamente personal, desplegada en ese texto con la intención de hacer frente a la prevalencia exagerada de la filosofía francesa que Gaya percibió en el ámbito del arte ${ }^{5}$.

En el fragmento que citamos, la estrategia discursiva dual tan prominente en la obra de Gaya se manifiesta con gran nitidez; no queda muy claro, sin embargo, a qué se refiere exactamente cuando habla de 'tener Pensamiento' y cómo se diferencia del mero 'pensar', ya que se refugia en afirmaciones algo mistificadas, desplegadas en torno a la metáfora del fruto (2010e: 857-858). En otro ámbito de absoluta centralidad

\footnotetext{
${ }^{5}$ «[L]a llamada cultura francesa [...] no ha sabido o no ha querido saber distinguir entre el simple mérito de pensar (que es algo así como masticar) y la viva y oscura riqueza de tener Pensamiento» (2010e: 856). Véase al respecto también la entrada en su diario del 24 de enero de 1953, en la que alega que «los franceses carecen de ... pensamiento; sólo tienen inteligencia» (2010c: 430-431).
} 
en su obra, no obstante, la diferencia entre las dos partes de una pareja de términos casi idénticos se revela con mayor claridad: el arte. Aquí, el murciano se pronuncia a menudo sobre la brecha que separa, en su perspectiva, el mero 'arte' de la más elevada 'creación', o también el 'arte natural' o 'arte verdadero' de su forma claramente inferior, que Gaya designa como 'arte artístico'7. Esta diferencia es tan esencial para Gaya y su entendimiento del medio artístico que se desarrolla ya tempranamente en El sentimiento de la pintura, donde aclara acerca de la primera noción: «[E]1 arte es realidad, el arte es vida él mismo y no puede, por lo tanto, separarse de ella para contemplarla; el arte no es otra cosa, no puede ser otra cosa que vida, carne viva». El 'arte artístico', , por el contrario, esa otra cara de la misma moneda, es un arte «ensoberbecido, algo separado, artificial, abstracto» y autorreferencial hasta la onfaloscopia, de modo que «se llegó con facilidad a ese ahogo del arte por el arte» (2010a: 32-33).

La coincidencia entre las esferas del arte y la vida que Gaya postula aquí como criterio del buen hacer creativo y creador habla del profundo apego del murciano -hijo de su tiempo como lo somos todos- a un proyecto típicamente moderno. La postmodernidad, ya plenamente en marcha durante el último tercio de su vida, rompió con tales pretensiones, volvió a afirmar el arte como institución social, y con ello, también la brecha entre la esfera del arte y la vida 'cotidiana' (Žižek, 2005: 122). Más interesantes que tales reflexiones sobre la periodización artística y cultural, sin embargo, es descubrir lo que las contrastaciones del murciano revelan sobre el objeto de sus búsquedas, llevadas a cabo mediante el método epistemológico dual.

\footnotetext{
${ }^{6}$ Muy patentemente por ejemplo en Gaya (2007: 75).

${ }^{7}$ Son muchos los momentos de su obra escrita que tematizan esta diferenciación particular. Para una lograda síntesis, véase el capítulo «Arte, no-arte y arte artístico» en la monografía de Miriam Moreno Aguirre (2018: 300-313).

${ }^{8}$ El término de 'arte artístico' fue introducido en el discurso estético por Ortega, quien lo empleó en su célebre ensayo «La deshumanización del arte» para referirse a las nuevas formas de expresión artística surgidas en torno a las vanguardias 'clásicas'. La obra escrita de Gaya no permite la comprobación definitiva de que el murciano conociera el influyente texto orteguiano; su propia concepción del 'arte artístico', en todo caso, dista mucho de la del gran pensador español. Como lo venimos esbozando, Gaya entiende como 'artístico' aquel arte que se define principalmente por modas y vanidades, que carece de sustancia verdadera, un arte casi 'decorativo' y deshonesto, para el que el marbete de 'artístico' también implica una valoración moral. Para Ortega, por el contrario, el calificativo de 'artístico', aplicado al nuevo arte de las vanguardias, pone de relieve, ante todo, una división epistemológica entre sus receptores: «[E]l arte nuevo divide al público en dos clases de individuos: los que lo entienden y los que no lo entienden; esto es, los artistas y los que no lo son. El arte nuevo es un arte artístico». Esta estimación contrastiva, como lo señala Ortega a renglón seguido, no es sino una constatación de las circunstancias; no implica juicio estético o moral alguno: «Yo no pretendo ahora ensalzar esta manera nueva de arte, y menos denigrar la usada en el último siglo. Me limito a filiarlas, como hace el zoólogo con dos faunas antagónicas» (1966: 359).
} 
"Volver a un origen desnudo". Refracciones de incompletitud ontológica en la obra pictórica de ...

Así, uno pronto se da cuenta de que en las contemplaciones gayescas no hay una sola superficie sobre la que compiten definiciones en algún grado divergentes -esto se correspondería a un modo más espontáneo y cotidiano de pensar: no siempre estamos de acuerdo sobre qué exactamente es el arte, pero a fin de cuentas las congruencias prevalecen sobre las diferencias-, todo lo contrario: hay una definición sencilla y abierta, y después, detrás de las cosas, se esconde otra dimensión nueva que se opone a los entendimientos inmediatos y ya conocidos.

Volviendo ahora, tras esta breve digresión-no-digresión, al tema del desencanto de Gaya en la capital francesa y su perentorio rechazo de la crítica artística, no podemos sino manifestar nuestro acuerdo con Andrés Trapiello, quien relacionó la desazón del murciano con su primera visita al Museo del Prado, realizada, con diecisiete años, poco antes de emprender el viaje a Francia. Trapiello señala que el murciano apreciaba el gran museo madrileño como «algo único y firme», un lugar que atesora la pintura, que la encierra al tiempo que la celebra. Allí se encontraba $-\mathrm{y}$ aún se encuentra- «dormida en sus siglos, silenciosa en sus muros», y sin embargo tan rica, espléndida y fascinante que le produjo un gran «deslumbramiento» al joven Gaya, a consecuencia del cual su encuentro parisino, en la estimación de Trapiello, no pudo sino tener el final que tuvo: llegó a la conclusión de que aquella pintura, la que encontró en el Prado, era «mucho más viva que toda la que barnizada de actualidad gritaba desde los escaparates» (2000: 20) de la capital francesa.

Agudizando esta idea en la línea de que lo que venimos señalando sobre la dualidad fundacional en el pensamiento de Gaya, podríamos decir razonadamente que el pintor, en esa su primera visita al Prado, se topó con la Pintura -duradera, esencial, atemporal- mientras que en el triste periplo con parada en París no encontró más que pinturas con minúscula, apreciadas, hasta glorificadas por los mercaderes del bazar del arte, pero en realidad irremediablemente ancladas en superficialidades, gobernadas por el vaivén de modas y gustos, y permeadas de una orientación estrictamente mercantil. En la perspectiva de Gaya, los críticos, por eruditos y aclamados que sean, forman parte de ese bazar (2010a: 32-34), y es más: cuanto más peritos en la materia, menos natural y espontáneo, más mediado e 'inauténtico' su acceso a las creaciones artísticas ${ }^{9}$. En esto reside, para nosotros, la razón última -seca, teórica y nada emocional- que subyace en el por momentos hasta furibundo juicio negativo de Gaya al sector de la crítica.

\footnotetext{
${ }^{9}$ Véase Gaya (2010f: 938-939). No podemos dejar de señalar la sorprendente proximidad del planteamiento de Gaya al conocido ensayo de Susan Sontag, «Against Interpretation», y en particular a la célebre tesis final del mismo: «In place of a hermeneutics we need an erotics of art» (1982: 14). Como Gaya, Sontag se pronunció en favor de un acceso más afectivo, espontáneo y sentido, a las obras de arte. Lástima que concluyera su escrito con la frase que, a nuestro modo de ver, debería haberlo encabezado, pues queda bastante nebuloso lo que Sontag entiende concretamente bajo el sin duda sugerente término de 'erotismo del arte'.
} 


\section{La dualidad de las cosas: apariencia y esencia, superficie y secreto}

La doble figura epistemológica tan presente en el pensamiento de Gaya, esa búsqueda de lo 'real' y verdadero tras las apariencias de la superficie, evoca una serie de asociaciones con diferentes ideas y corrientes a lo largo de la tradición filosófica occidental. Aunque las referencias manifiestas a otros pensadores no abundan en su obra escrita (con la excepción, tal vez, de Nietzsche, quien ocupa en una posición relativamente destacada en el desenvolvimiento del discurso de Naturalidad del arte (2010f: 934-938), su búsqueda del sustrato 'real' inherente a los términos y fenómenos que contempla, de una verdad esencial más allá de la superficie y la apariencia comparte rasgos con las propuestas filosóficas más variadas, desde la piedra angular del pensamiento europeo que es la parábola de la caverna, fundamento de la ontología y la epistemología platónicas, pasando por (no tan) remotos ecos de gnosticismo - por momentos, sus textos exhiben una notable impronta esotérica, dejan al pintor 'verdadero' en el lugar del iniciado quien pugna, a menudo en balde, contra las corrupciones de la apariencia engañosa ${ }^{10}$ - hasta la separación de un dominio fenoménico, matérico y perceptible, de otra dimensión suprasensible, reino inimaginable de los noumena en el idealismo kantiano, poblado después, en la estela del gran pensador alemán, por cosas-en-sí de diversa índole.

Sería un exceso, desde luego, querer leerle a Gaya una orientación consistente con alguna de las corrientes que acabamos de mencionar, tanto por la dificultad de la tarea (¿qué es, en realidad, ser kantiano, platónico, gnóstico?) como por la propia naturaleza de su discurso, que brilla precisamente por sus aristas idiosincrásicas e híbridas. Sea cual sea, pues, la afiliación filosófica que uno le quiera suponer a Gaya -él mismo seguramente se hubiera desentendido de tales malabarismos de peritos (2010a: 33-34) de un plumazo-, la doble epistemología se confirma como elemento central y estructurante a lo largo de buena parte de su obra escrita, aunque su visibilidad se acrecienta a partir de la vuelta a Europa, y en particular, las estancias del pintor en tierras italianas, periodo clave en la gestación de sus formas e ideas maduras.

Hemos conocido ya la fundamental dualidad que Gaya percibe en el dominio del arte, articulada en el desigual binomio del 'arte (verdadero) vs. arte artístico'. La misma se ve enriquecida, más tarde, por otros dos conceptos dobles, uno dirigido hacia la apreciación del arte, y el otro centrado en el quehacer principal del artista:

\footnotetext{
${ }^{10}$ Nos referimos aquí, por ejemplo, al ensayo ya citado de «El fruto original», que contrapone, podría decirse, el entendimiento 'terrenal' con otro 'divino', más allá de los engaños de la materia y la realidad. Son muestra de esa actitud cripto-gnóstica también muchos otros momentos en la obra de Gaya; véase sobre toda la 'cajita de aforismos' que son sus «Anotaciones» $\mathrm{y}$ «Otras anotaciones» (2010b: 253-268).
} 
"Volver a un origen desnudo". Refracciones de incompletitud ontológica en la obra pictórica de ...

el pintar. En Naturalidad del arte (y artificialidad de la crítica), el último ensayo del murciano, el método dual se despliega otra vez con fuerza: para ser capaz de acceder de veras a una obra de arte, alega Gaya, no hace falta simplemente 'entenderla', sino, antes bien, 'comprenderla'. Estamos, por consiguiente, nuevamente ante una pareja de términos que, en un marco semántico habitual, se considerarían sinónimos. No así, sin embargo, para Gaya: bajo 'entender' se refiere un acceso intelectualizado a la obra de arte, nutrido por el estudio y la costumbre, en fin, algo que «se puede conseguir con un poco de tiempo, una cierta inteligencia y una buena cantidad de aplicación» (2010f: 931). Aun así, 'entender' -el modo de acceso prevalente en la crítica y la historiografía del arte- vale poco en comparación con el shock iluminador que es el 'comprender', «un acto más bien seco y rotundo, muy rápido, además, pues a la sola aparición del sujeto en cuestión, éste debe ser instantáneamente comprendido por nosotros de un solo golpe, de una vez por todas, o no lo comprenderemos nunca» (2010f: 931). En cierta proximidad a las reflexiones sobre pensar y tener pensamiento de El fruto original, Gaya incide aquí en la fundamental imposibilidad de alcanzar la comprensión por vía del aprendizaje consciente, por la cultura y el intelecto de uno. 'Comprender' ha de ser algo, si no innato o insuflado por un aliento divino, al menos profundamente arraigado en el inconsciente del receptor, algo de lo que el sujeto es capaz o no, pero que en absoluto puede ser adquirido a través de la dedicación estudiosa, la cual, en realidad, tiene incluso un efecto adverso, pues mengua las probabilidades de que se produzca la alumbradora comprensión ${ }^{11}$.

La empresa del pintar, por último, el tercer elemento de esa tríada de 'proceso, resultado y apreciación de lo artístico' que se columbra a lo largo de la obra escrita de Gaya, se caracteriza asimismo -ya se habrá intuido- por una naturaleza fundamentalmente dual: por un lado está la pintura 'falsa', la que produce trabajos definitivamente inscritos en el sector del arte artístico, capaces de dar lugar a una multitud de 'entendimientos' diferentes, pero que poco o nada depararán, a buen seguro, para la comprensión. En el lado opuesto se situaría la buena pintura, aquella que se deshace de vanidades y juegos superficiales, la que no busca deslumbrar o engatusar a su contemplador, sino descubrir y captar los secretos recónditos de la vida y la realidad. El contraste entre las dos no se ha articulado de manera más

\footnotetext{
${ }^{11}$ Mientras que las dos partes del binomio entender/comprender en nuestra estimación son prácticamente sinónimas en castellano, puede resultar iluminador traer a colación aquí la pareja italiana análoga de capire vs. comprendere, puesto que el segundo de estos dos verbos exhibe una connotación espiritual, tan esencial para el murciano, que su pendant español desconoce. Decimos esto, porque el shock iluminador que es el comprender, lo experimenta Gaya particularmente ante los cuadros de Tiziano, durante un periodo, además, marcado por una gran proximidad intelectual a la cultura y la lengua italiana.
} 
sugerente y plástica que en los dos cuartetos del soneto De pintor a pintor, que contrapone ambas concepciones del oficio artístico, la 'falsa' y la 'verdadera', en un balance poético (2010d: 637):

$$
\begin{gathered}
\text { Pintar no es ordenar, ir disponiendo, } \\
\text { sobre una superficie, un juego vano, } \\
\text { colocar unas sombras sobre un plano, } \\
\text { empeñarte en tapar, en ir cubriendo; } \\
\text { pintar es tantear -atardeciendo-- } \\
\text { la orilla de un abismo con tu mano, } \\
\text { temeroso adentrarte en lo lejano, } \\
\text { temerario tocar lo que vas viendo. }
\end{gathered}
$$

El ámbito del arte en su integridad, tanto en el lado del creador como en el de su receptor, se constituye para Gaya en términos de una búsqueda incierta, un «tantear», «temeroso» al tiempo que «temerario», una precaria indagación que sólo se da cuenta de lo que busca cuando lo encuentra. Esta empresa -sondear los misterios de la pintura- se percibe con tal urgencia en su obra que un buen número de críticos se han acercado a la misma -bajo signos distintos al nuestro en este ensayo- en sus apreciaciones del arte gayesco, desde el temprano comentario de su gran amiga María Zambrano hasta la recentísima aportación de Elide Pittarello de 2018. Cada uno de ellos contempla la plural y polifacética obra desde su atalaya personal; todos inciden, no obstante, en la importancia que tuvo para Gaya el encontrar una verdad pictórica más allá de la superficie.

En el texto dedicado al amigo murciano de sus Lugares de la pintura, Zambrano, una de las primeras en comentar su obra, comparte con él esa noción de pintura con tintes esencialistas: más que término técnico o denominación categorial, en la estimación de la filósofa malagueña 'pintura' denota la idea de la misma, que puede -o no- estar presente en las obras particulares plasmadas en el lienzo (1989: 210). Para Zambrano, lo más visible de una obra es asimismo portador de lo más secreto y valioso, como se evidencia ya en las primeras líneas de su ensayo: «De la pintura, como de todas las cosas visibles, lo más decisivo es el modo de su presencia; lo más 'superficial' es lo que puede darnos la clave de lo que encierra» (1989: 209). En esta apreciación, lo visible y lo escondido, lo superficial y lo profundo van de la mano, se sitúan en gran proximidad. Otros comentaristas del arte gayesco, sin embargo, no comparten de lleno tal observación, incidiendo, antes bien, en la distancia significativa que en él se percibe entre superficies y profundidades. 
"Volver a un origen desnudo". Refracciones de incompletitud ontológica en la obra pictórica de ...

Así por ejemplo Jacobo Muñoz Veiga, quien evalúa la categoría de 'realismo' aplicada con frecuencia a las creaciones de Gaya, constatando que, antes de tratarse de un realismo «'externo'» (2011: 188) -léase, a nuestro parecer, verista y superficial-, el del pintor murciano ha de entenderse como un realismo «metafísico, esencial, trascendente, hecho carne en la más pura transparencia», cuyo misterio supremo no reside «en su materialidad concreta o en su textura formal, sino en su condición de substancia verdadera, secreta, de la realidad, capaz pues de autotrascenderse» (2011: 188). La trascendencia es el elemento central también en la apreciación de Elide Pittarello, quien entremezcla de forma personal una aproximación en atenuada clave idealista con lo que nosotros entendemos como alusión en passant a las enseñanzas de Lacan:

[E]l fin de su arte es darle consistencia visible al más allá de lo real, a lo trascendente. Ambas dimensiones son indisociables y cooperan incesantemente. Si no está oculto, ese objeto del deseo y móvil de la forma no se puede evocar, no hay posibilidad de que aparezca (2018: 33).

Al contrario de Zambrano, para quien la pura superficie ya 'lo es todo', donde lo invisible se esconde precisamente en lo visible, Pittarello subraya la necesidad de cavar más hondo, de buscar ese objeto del deseo, el objet petit a en términos del gran psicoanalista francés, en las profundidades de la pintura gayesca.

José Muñoz Millanes, por último, otro avezado comentarista del arte gayesco, se suma a lo establecido por los demás intérpretes, formulando su propio veredicto, no obstante, en términos más formalistas, en una línea relativamente próxima a la que adopta este ensayo nuestro:

[L]a forma por él propugnada no es la forma 'elocuente' o abiertamente expresiva (la forma estable y reproducible que lo real adquiere en el ojo del pintor), sino algo huidizo y de difícil visión: la forma orgánica, viva y única, cuyo tránsito adopta un ritmo casi imperceptible constitutivo de esa paradójica expresividad reticente (1994: 551).

Como se ve, los cuatro intérpretes aquí reseñados coinciden en que el realismo de firma gayesca es más que mero retrato de lo real, encierra en sí un elemento, un $\mathrm{X}$, que sobrepasa los confines de la pintura representativa y alberga la chispa, el secreto, de su obra. Cada uno de ellos encuentra un nombre distinto para ese X, huidizo y subyacente, aunque crucial para la estética de Gaya: para Zambrano es la presencia, Muñoz Veiga y Pittarello operan con conceptos como metafísica, esencia o trascendencia, y Muñoz Millanes introduce la noción de la forma orgánica que se 
opone a la forma 'elocuente', abierta. Son, sin duda, todos ellos acercamientos válidos y sugerentes; nosotros mismos, para la segunda parte de este ensayo, proponemos otro acercamiento adicional, no adverso, desde luego, a los que acabamos de revisar, sino a modo de complementación y enriquecimiento: comprender ese $\mathrm{X}$, el factor que les otorga potencia y profundidad a las pinturas de Gaya, como reflejo de la fundamental incompletitud ontológica de la realidad, según la ha desarrollado el pensador esloveno Slavoj Žižek.

\section{La realidad, ¿un videojuego?}

Dada la aún escasa notoriedad (y el destacado interés) de la ontología žižekiana, estimamos conveniente comenzar nuestro análisis de la obra pictórica de Gaya con un breve excurso sobre la misma, incidiendo también en las implicaciones que tiene para la creación y el estudio de las artes plásticas. En lo esencial, Žižek mantiene que lo que percibimos como realidad (ya sea el 'mundo fenoménico' en la línea idealista a partir de Kant, ya sea la 'realidad simbólica' en términos de Lacan) se encuentra en una situación de inconsistencia consigo mismo, en un estado abierto e indeterminado, plagado de perturbaciones, fallas e incongruencias. Se trata de una concepción 'típicamente žižekiana' en cuanto que sigue una lógica contraintuitiva, puesto que por lo común se tendería a asumir -con independencia de la tradición filosófica a la que uno se adscribe- que la realidad se concibe 'completa' por definición. Žižek, no obstante, afirma precisamente lo contrario mediante un recurso al concepto lacaniano del pas-tout, a saber, postula que la realidad es no-toda ${ }^{12}$, no implicando así, sin embargo, que exista otro plano de la misma eternamente inaccesible para el sujeto -el esloveno rechaza rotundamente la idea kantiana de la existencia de una esfera nouménica más allá de lo fenoménico-, sino que la realidad misma se forma y constituye de modo abierto, indefinido (2005: 88-93, 297-298). Ese razonamiento entraña, asimismo, la transposición de una limitación, de un obstáculo epistemológico -en la línea de que 'la realidad puede que aparente incompleta porque no somos capaces de registrarla de forma exhaustiva' - en un hecho ontológico (2006: 20-28; 2012a: 145-151).

Las bases filosóficas que Žižek trae a colación para elaborar esa idiosincrásica visión de la composición elemental de nuestra realidad son múltiples, aunque dos

\footnotetext{
${ }^{12}$ Esta observación ha sido prefigurada, intuida o anticipada de diversos modos por un buen número de creadores y pensadores anteriores a Lacan y Žižek. Para el marco del presente número es sobre todo interesante señalar que se percibe tanto en el concepto del arte según Miguel Ángel como en la célebre Oratio de hominis dignitate de Pico della Mirandola; referencias ambas señaladas por nuestra estimada colega Belén Hernández González que incluimos aquí con gratitud.
} 
"Volver a un origen desnudo". Refracciones de incompletitud ontológica en la obra pictórica de ...

de ellas se confirman como particularmente relevantes: el pensamiento de Schelling, en especial a partir de su Freiheitsschrift, así como el ya mencionado concepto del no-todo, fruto de las investigaciones de Lacan en torno a sus fórmulas de sexuación. Schelling proporciona la noción del Grund -un esencial impulso para las elaboraciones posteriores de Žižek- como el oscuro fundamento sobre el que se yergue la Existenz, la constitución de la realidad según parámetros racionales, la creación ordenada, sistemática y 'lógica', para la que el Grund actúa como una suerte de oscura base proto-ontológica, turbia e impenetrable, que sirve como el soporte para la expansión del universo del logos (Schelling, 1989: 163).

De Lacan, en cambio, deriva Žižek el carácter ilimitado e ingobernado que postula para su diseño ontológico. En sus reflexiones sobre la sexuación, el francés propone dos fórmulas antinómicas, una masculina y otra femenina. Žižek aprovecha las mismas -despojadas de su contexto específico, en su capacidad de proposiciones lógicas- para apuntalar su visión sobre composición y naturaleza de lo existente, afirmando que, en lugar de regirse por la lógica masculina (que en este contexto resultaría en dos dimensiones diferenciables, una sensible, fenoménica, y otra 'más allá', suprasensible), la realidad material obedece al pendant femenino, lo que implica que, al tiempo que no se produce el caso de una excepción fundante -a saber, no existe una dimensión suprasensible-, esa realidad se concibe como constitutivamente abierta, no-toda (2012a: 739-771).

Las particularidades del diseño ontológico de Žižek son complejas; se trata de un modelo gestado durante un largo periodo de su trayectoria, una piedra angular relativamente fija en el tan maleable - e inmenso- conjunto teórico que es su pensamiento. A la pregunta algo cándida de cómo uno ha de imaginarse una ontología de semejantes características, no obstante, el esloveno ofrece una respuesta sorprendentemente sencilla: nuestro mundo incompleto ha de entenderse de manera análoga a un entorno virtual, como se encuentran a menudo en determinados tipos de videojuego (2012a: 743-744) ${ }^{13}$ : el jugador puede explorar, en exclusiva, aquellas zonas del entorno que anticipan esa exploración; así, por ejemplo, puede darse el caso -admitidamente simplón- de una casa que consiste únicamente en una fachada, a la vista de que, al interior del mundo diegético de la simulación, resulta imposible entrar en ella. Tal explicación, lo reconoce el propio Žižek, acarrea fuertes implicaciones teológicas: un videojuego, a fin de cuentas, es creado por alguien. Para el caso del gran juego que es la realidad, entonces, todo ello significaría que el creador del mismo -al que solemos denominar 'Dios' - no fue capaz de prever las hazañas de la inteligencia, la industria y el espíritu humanos, a tal punto que dejó las cosas 'a medias', con la esperanza de que nosotros, los jugadores, no nos

\footnotetext{
${ }^{13}$ La metáfora del videojuego empleada por Žižek es un préstamo de N. Fearn (2005: 77).
} 
fuéramos a enterar. Žižek ilustra todo ello refiriéndose a los, a menudo paradójicos y desconcertantes, descubrimientos de la física subatómica:

The idea is that the god who created or 'programmed' our universe was too lazy (or, rather, he underestimated our intelligence): he thought that we humans would not succeed in probing into the structure of nature beyond the level of atoms, so he programmed the Matrix of our universe only to the level of its atomic structure-beyond that, he simply left things fuzzy (2012a: 743-744).

A pesar de los muchos momentos de especulación teológica que se descubren en su obra (y de su auto-denominación como 'cristiano ateo'), Žižek señala sobre lo anterior que la figura del creador, tan útil aquí para facilitar el entendimiento de su modelo, no es el centro imprescindible de un mundo incompleto; aquí, la dificultad estriba, antes bien, en aceptar la existencia indeterminada aun a sabiendas de que no es obra de ningún dios creador (2012a: 740).

Los hallazgos en el campo de la física le sirven al esloveno como confirmación científica de sus postulados, pero el ámbito de las ciencias exactas -si bien lo emplea, a modo de justificación, con frecuencia y gusto ${ }^{14}$ - no es el único ni el primero en registrar la incompletitud de la realidad: según las tesis de Žižek, a partir de la eclosión del modernismo con su caleidoscopio de formas, temas y procedimientos, es sobre todo el arte el medio que registra e inscribe en sus obras las vicisitudes de un mundo incompleto, tambaleante y en continua mutación. Entre las muchas formas de expresión artística destaca, al parecer de Žižek, sobre todo la pintura. Cierto es que el cine y la literatura también conocen sus métodos para visualizar, y así visibilizar, la ontología incompleta que determina nuestra realidad. La pintura, no obstante, y sobre todo aquella que busca la superación del realismo en favor de disoluciones pictóricas, menos apegadas a lo plenamente visible y más orientadas hacia la sustancia misma, se confirma especialmente propicia para captarla, según lo constata Žižek en una de sus características preguntas retóricas:

Are not the 'stains' which blur the transparency of a realist representation, which impose themselves as stains, precisely indications that the contours of constituted reality are blurred, that we are approaching the pre-ontological level of fuzzy proto-reality? (2012a: 744)

«Modernism begins when you look at the world as an unfinished work» (2012b: 19:24-19:34) es la tesis central del esloveno en una de sus conferencias sobre la ontología indeterminada y sus plasmaciones en el arte. Pocos veredictos más acertados se nos ocurren sobre la creación de Ramón Gaya, un arte que descubre ${ }^{14}$ Véase por ejemplo su amplio tratado del año pasado, Sex and the Failed Absolute, y en particular el capítulo «Corollary 3: The Retarded God of Quantum Ontology» (2020: 273-307). 
"Volver a un origen desnudo". Refracciones de incompletitud ontológica en la obra pictórica de ...

su modernidad -y también su esplendor, su fuerza, su chispa, su misterio- cuando, motivado por las experiencias deslumbrantes del pintor en Italia e informado, de siempre, por la búsqueda de una verdad pictórica, empieza a contemplar el mundo como obra inacabada.

\section{Las ontologías pictóricas de Ramón Gaya}

Cada una de las etapas de creación en la trayectoria del murciano conoce sus momentos estelares; es a partir de su retorno a la vieja Europa, sin embargo, y en particular en el momento de sus prolongadas estancias en tierras italianas, cuando su arte empieza a registrar la indeterminación ontológica, esa apertura de la realidad en sus partes más fundamentales teorizada por Žižek. Entre los primeros testigos de ello encontramos piezas como Las luces del Ponte Vecchio del año 1958, ejecutada poco tiempo después de su vuelta definitiva en 1956, o la más tardía de la Riva degli Schiavoni (1978) sobre un motivo del entorno urbano de Venecia, a buen seguro la ciudad italiana que más le fascinó. La aparición paulatina de los primeros indicios de incompletitud y borrosidad de lo existente en las obras de Gaya se realiza así al compás de su establecimiento en Italia tras los años de exilio en México.

Las luces del Ponte Vecchio se encuentra entre las primeras obras que visualizan, aún tierna, tentativamente, un nuevo acercamiento de Gaya a la sustancia de nuestra realidad, a lo que él suele llamar -es evidente, a nuestro juicio, esta definición amplia- 'naturaleza'. La pieza se inserta todavía en un horizonte realista, parte en lo esencial de la percepción visual de la escena. Un elemento de ella salta a la vista, no obstante, porque rompe con el gusto serenamente impresionista que caracteriza la composición en su total; si de una fotografía se tratase, podríamos llamar ese elemento, en pos del gran Roland Barthes, el punctum de la obra, el objeto parcial que desencaja, desconcierta, nos pincha: la etérea farola que se yergue, en el lateral izquierdo, al pie del puente. Mientras que los elementos restantes exhiben una factura uniforme (una ejecución ligera y veloz, que subraya lo gestual al tiempo que le resta precisión; un favorecimiento de la Stimmung en sentido schilleriano en lugar de una representación fidedigna de lo visto y lo visible, que no obstante constituye la base de la obra), la farola desentona gratamente. Incluso llamar ese curioso objeto 'farola' es, en verdad, aventurarse, puesto que no cumple con la función asignada. El color del cielo y el alumbrado de calles y edificios visible en otra parte de la pieza -en concomitancia, naturalmente, con su título- transmiten la idea de que se trata de la captación de un atardecer, para el pintor murciano la hora de la transfiguración, el momento en que el mundo revela su plasticidad, su carácter cambiante y fluido 
con mayor claridad. La enigmática farola, sin embargo, aún no se ha encendido; de hecho, parece que ni siquiera se ha diseñado para ello. Se trata, antes bien, de un extraño recipiente vítreo colocado sobre un poste, una urna transparente que no encierra más que un trozo de cielo.

En invenciones como esa se perciben los primeros tambaleos en los antaño estables mundos pictóricos de Gaya; una tendencia que se va confirmando y consolidando a medida que se Gaya se establece, ya definitivamente, en Europa. Así, en el segundo trabajo que acabamos de mencionar, la Riva degli Schiavoni, descubrimos una suerte de 'confirmación pintada' de aquel juicio del murciano sobre la famosa urbe acuática recogido en su diario: «Venecia es líquida, transparente, di vetro» (2010c: 430). Con un gesto más ágil que el que se percibe en trabajos anteriores, Gaya diseña una veduta alegre y soleada de unas de las calles más nobles y señaladas de Venecia, en la que el entorno arquitectónico -y también naval- todavía retiene cierto apego a las tradiciones de representación realista. Los transeúntes y sus sombras, en cambio, se disuelven en risueñas manchas moteadas sobre el lienzo, gotas felices que pueblan la calle con sus brincos, en un trabajo que revela no sólo un profundo conocimiento de lo existente, sino que también precipita un aire de optimismo duradero.

De vuelta a España, Gaya se muestra fiel a sus descubrimientos y aprendizajes en Italia. Son numerosas las obras que exhiben, en menor o mayor grado, una tendencia a la disolución, a la demostración artística de que los fundamentos de nuestra realidad son más inestables y endebles de lo que se pudiera percibir en lo cotidiano. Tal tendencia no conoce limitación alguna en cuanto a técnica, motivo o formato, la encontramos tanto en obras a todas luces 'menores' -aunque no por ello menos significativas-, como lo puede ser la pequeña acuarela La huerta de Murcia (el reguerón) del año 1982, como también en lienzos de gran formato e impacto, entre los que destaca el retrato de su mujer, En la mecedora (Isabel Verdejo), pintado un año más tarde en 1983.

En el primer trabajo de esta desigual pareja, Gaya vuelve a orientarse hacia una temática según él de siempre presente en los espesores de su psique y su experiencia vital: la huerta. En el breve, aunque llamativo escrito «Huerto y vida», el pintor revela que el primero de sus recuerdos está vinculado, precisamente, con ese lugar tan emblemático de la región murciana. Más que tratarse de un recuerdo constituido y completo, de una escena recordada en su totalidad, sin embargo, se trata de uno curiosamente parcial, de una única rama de nisperero retenida en la memoria del pintor sin que tuviera constancia de ningún dato sobre el contexto específico: 
"Volver a un origen desnudo". Refracciones de incompletitud ontológica en la obra pictórica de ...

[L]o cierto es que aquí todavía no hay nadie, personne, no hay persona, sólo esa rama sin qué ni por qué, o sea, sin argumento, sin sujeto, incluso sin representar o simbolizar cosa alguna, en una especie de... estar puro, mondo y lirondo, como algunas de esas flores, rodeadas de vacío, que aparecen en las viejas pinturas chinas y japonesas (2010b: 232).

Amén de ser como una suerte de vaticinio sobre el motivo que, años más tarde, coronaría su carrera artística -el Vaso de geranios que comentaremos más adelante-, este pasaje invita a la especulación razonada de que la de Gaya siempre fue una percepción sumamente analítica. Mientras que es un hecho científicamente comprobado que perspectiva y posición subjetiva en el recuerdo varían en función de la antigüedad del mismo - a saber, los recuerdos más recientes se evocan, por lo común, en primera persona; los más añejos, en cambio, tienden a la imaginación desde un punto de vista elevado, en cierto modo desubjetivado, como si de una escena de película se tratara-, la memoria de un objeto parcial, flotando atemporal en el vacío, como lo describe Gaya, es ciertamente llamativa. Excesivo sería, naturalmente, vincular esa temprana anécdota directamente con nuestra tesis sobre una ontología incompleta plasmada en sus trabajos pictóricos; bien puede considerarse, eso sí, prueba de que Gaya, desde muy temprano, disponía de una mente y un ojo muy propicios para captar todo aquello que no se les ofrece tan fácilmente a las primeras vistas.

Ese es el horizonte de propensión analítica en que se inserta la alegre obra de pequeño formato del 82, que transforma el motivo de la huerta en un aluvión de verdores. La referencia tangible de la pequeña caseta del fondo, flanqueada por un par de palmeras, se distingue con claridad, la sustancia misma de la huerta, sin embargo, la vegetación, la naturaleza, aparece aquí como examinada bajo el microscopio. Las hojas se convierten en células vivas, resplandeciendo en una rica gama de tonos verdes, frescos y lozanos; las plantas se deshacen en su propia sustancia, mostrándonos, más que la configuración de una escena de paisaje, una suerte de meditación sobre el dinamismo, la pujanza, el eros que encierra todo lo natural.

El soberbio retrato de Isabel Verdejo, por el contrario, se decanta por otro modo distinto de mostrar lo indefinido del sustrato de nuestra realidad: mientras que obras como la Huerta optan por una suerte de 'análisis microscópico' de su contenido pictórico, disolviéndolo en diminutos puntos que oscurecen la sustancia pintada al tiempo que la aclaran (un método, por cierto, que nada tiene que ver con otras meditaciones sobre lo puntiforme, por ejemplo de la mano de Seurat), En la mecedora se centra en un juego de lo pintado y lo no pintado. Pudiera entenderse como interpretación más literal de lo incompleto -un juicio no desacertado, desde luego-, aunque en nuestra estimación Gaya reflexiona en esta obra, una representación de su mujer en un momento determinado, irrecuperablemente pasado, en torno al hecho 
de que la incompletitud de la materia se refleja también en el propio sujeto, en su conciencia y sus recuerdos. Ningún recuerdo es completo; una observación en la que se suelen entrecruzar, cuando se somete a la reflexión intelectual, consideraciones sobre la capacidad limitada y selectiva de la memoria humana con otras de tipo epistemológico que resaltan la imposibilidad, también filosófica, de registrar y retenerlo todo. Con Žižek, sin embargo, se nos ofrece otro modo de entender ese fenómeno: los recuerdos son borrosos, parciales e incompletos porque el mundo recordado, en su pura materialidad, también lo es (2006: 167-168; 2012a: 147). Para nosotros, entonces, En la mecedora, con su bellísima figura femenina en el centro, rodeada de contornos que se deshacen en la nada, es ante todo eso: una representación, sentida y personal, de la transformación de un obstáculo epistemológico en un hecho ontológico, magistralmente articulada en un esplendoroso retrato.

Ninguna apreciación del arte de Gaya es completa, naturalmente, sin mención de sus numerosos homenajes, su manera personal de celebrar a aquellos creadores que más estimularon la imaginación del murciano, aquellas obras que evocaron en él la más profunda admiración. También en ellos se detecta una clara inclinación hacia lo inestable y la disolución, una tendencia que comienza a cuestionar la solidez temprana de ese tipo de trabajos en favor de una difuminación y una incompletitud cada vez más pronunciadas. A la prueba, consideremos el contraste entre dos piezas del conjunto de homenajes a Velázquez: el Felipe Próspero del año 1951 y las etéreas Meninas, realizadas años después en 1996. La primera de las dos no desconoce una cierta borrosidad en la ejecución; sorprende, ante todo, el rostro difuminado del infante, cuyas facciones se han vuelto imperceptibles. Alrededor de esa representación en miniatura del famoso lienzo de Velázquez, no obstante, se perciben con nitidez un ramo de flores y un vaso de agua, objetos que suelen acompañar este tipo de pinturas gayescas. La obra del 96 sigue las pautas compartidas por la mayoría de los homenajes (Moreno Aguirre, 2018: 202-222) -también aquí un ramo de flores y un vaso de agua-, aunque la acrecentada gestualidad de la pieza salta a la vista: la composición se configura, o tal vez se desintegra, en rápidas pinceladas, el abandono del principio realista se evidencia, también aquí, con solvencia y pujanza.

El viaje pictórico al corazón de la pintura, y con ella, al de la sustancia misma -esos dos planos inextricablemente entrelazados en la obra y las ideas de Gaya-, encuentra su punto final en la pieza Vaso con geranios, la última pintura del murciano, ejecutada en 2004. En ella, encontramos el cumplimiento, la soberbia realización final de ese «volver a un origen desnudo» (2010a: 46) del que Gaya nos habló, años atrás, en otra entrada de diario, en un trabajo que se ha de contemplar, estrictamente, como un destino, como regreso tras un largo trayecto a un origen cuyas características se desconocían al partir. «En general, el arte de Ramón Gaya tiende a ser cada vez 
"Volver a un origen desnudo". Refracciones de incompletitud ontológica en la obra pictórica de ...

más diáfano» (2018: 28), sentenció Elide Pittarello escueta y acertadamente en 2018; nosotros diríamos, en una línea próxima a la de la italiana, aunque basada en la teorización que informa este análisis, que: el arte de Ramón Gaya tiende a ser cada vez más consciente del carácter ontológicamente indeterminado de la realidad. No hay en la obra del murciano mayor momento de desnudez -completa, primigenia, existencial- que en el Vaso de geranios, ese cúmulo de pinceladas rápidas, precariamente superpuestas y movedizas como moléculas en baile. El que el propio Gaya durante su larga trayectoria se mostrara más bien escéptico hacia aquellas formas de representación artística que no provenían, en algún modo, de la percepción sensorial (2010c: 400-401), pero que, a pesar de ello, cerrara su æuvre con una pieza como los Geranios, situada en el espacio liminar entre figuración y abstracción, no es sino comprobación definitiva de nuestra tesis principal.

Decíamos antes que Gaya nunca declaró - con la excepción de aquellos atisbos de nietzscheanismo en Naturalidad del arte- abiertamente sus alianzas intelectuales. Muchas de las posiciones que contempla y negocia a lo largo de su obra escrita exhiben semejanzas con otras más firmemente insertadas en el horizonte de la filosofía occidental, según lo hemos visto de reojo en el segundo apartado de este ensayo. Qué duda cabe de que toda declaración de amistad con otro pensamiento encierra también, si bien en grado sumamente variable, un argumento de autoridad; las palabras del otro no suelen ser solamente inspiración, justificación o lugar de convergencia con las de uno mismo; a menudo también son amparo, protección y cobijo. Puede que Gaya, firme siempre en su hacer y pensar, no sintiera gran necesidad de resguardarse en las ideas de los demás. Claro está, desde luego, que tampoco le hacía falta.

Nosotros, por el contrario - menos firmes y más amantes de la palabra ajenano podemos cerrar nuestro análisis sin señalar un último punto de sugerente unión intelectual que hemos identificado en su obra: un nexo trivalente entre Gaya, Žižek y otro de los grandes pensadores fértilmente heterodoxos en nuestra tradición filosófica, Baruch Spinoza. El primero de ellos, Gaya, fue gran valedor de la naturaleza y lo natural, no tanto en un sentido literal, directo, sino comprendiéndola como sustancia causa sui, como las onduladas texturas de lo real opuestas a una artificiosidad muerta y artísticamente estéril. Spinoza, a su vez, equiparó la naturaleza-de la que tuvo, a todas luces, un concepto muy próximo al del murciano- con el mismo Dios, alambicando ese postulado con toda brevedad en la consabida fórmula de deus sive natura ${ }^{15}$; un planteamiento ese que desenmascara la figura de un dios creador 'personificado'

\footnotetext{
${ }^{15}$ Extraída de la cuarta proposición del libro cuarto de la Ética. En la traducción de Atilano Domínguez: «La potencia por la que las cosas singulares y, por tanto, el hombre conserva su ser, es la misma potencia de Dios o Naturaleza» (2000: 189).
} 
como mera pantalla que encubre nuestras limitaciones epistemológicas a la hora de registrar y comprender las redes causales que determinan la realidad. Žižek, por último, hace lo que mejor sabe hacer: radicalizar una idea para sonsacarle una verdad más profunda, al declarar que

Spinoza just needs to be taken more literally than he was ready to take himself: what if this lack or incompleteness of the causal network is not only epistemological but also ontological? What if it is not only our knowledge of reality but reality itself which is incomplete? In this case, is not the personalized notion of God also an indication [...] of the ontological incompleteness of reality itself? (2012a: 264)

Mediante la ya familiar operación, tan típicamente suya, de descubrirnos, una vez más, que una supuesta barrera epistemológica en realidad no es más que la articulación de un hecho ontológico, Žižek cierra el círculo. Lo divino es inmanente a la naturaleza, reside no en un plano más allá, sino en la sustancia misma. Eso lo sabían tanto Spinoza como Gaya. Pero el murciano dio un paso más: no sólo reconoció esa sustancia como fuente y origen de todo, sino que también se dio cuenta de la incompletitud de lo matérico, de la fundamental indeterminación del mundo que atesoró.

De lo contrario, no hubiera podido regalarnos sus magníficas ontologías pintadas.

\section{Bibliografía}

Fearn, Nicholas, Philosophy: The Latest Answers to the Oldest Questions, Londres, Atlantic Books, 2005.

Gaya, Ramón, Obra completa tomo IV. De Ramón Gaya a Juan Guerrero Ruiz (1927-

1953), edición, introducción y notas de Nigel Dennis, Valencia, Pre-Textos, 2000. Gaya, Ramón, Ramón Gaya de viva voz. Entrevistas 1977-1998, selección y presentación de Nigel Dennis, Valencia, Pre-Textos, 2007.

Gaya, Ramón, «El sentimiento de la pintura», en Obra completa, ed. de Nigel Dennis e Isabel Verdejo, Valencia, Pre-Textos, 2010a, págs. 27-93.

Gaya, Ramón, «Carta a un Andrés [y otros escritos]», en Obra completa, ed. de Nigel Dennis e Isabel Verdejo, Valencia, Pre-Textos, 2010b, págs. 187-329.

Gaya, Ramón, «Diario de un pintor, 1952-1953», en Obra completa, ed. de Nigel

Dennis e Isabel Verdejo, Valencia, Pre-Textos, 2010c, págs. 395-450.

Gaya, Ramón, «Algunos poemas», en Obra completa, ed. de Nigel Dennis e Isabel Verdejo, Valencia, Pre-Textos, 2010d, págs. 611-639. 
"Volver a un origen desnudo". Refracciones de incompletitud ontológica en la obra pictórica de ...

Gaya, Ramón, «Otros escritos: 1928-1996», en Obra completa, ed. de Nigel Dennis e Isabel Verdejo, Valencia, Pre-Textos, 2010e, págs. 853-927.

Gaya, Ramón, «Naturalidad del arte (y artificialidad de la crítica)», en Obra completa, ed. de Nigel Dennis e Isabel Verdejo, Valencia, Pre-Textos, 2010f, págs. 929-953.

Moreno Aguirre, Miriam, Otra modernidad. Estudios sobre la obra de Ramón Gaya, Valencia, Pre-Textos, 2018.

Muñoz Millanes, José, «Ramón Gaya en Italia: Venecia y el sentimiento de la pintura», Revista Hispánica Moderna, vol. 47, n. ${ }^{\circ}$ 2, 1994, págs. 543-554.

Muñoz Veiga, Jacobo, «Pintura y pensamiento en Ramón Gaya», Escritura e imagen, n. ${ }^{\circ}$ 7, 2011, págs. $183-188$.

Ortega y Gasset, José, «La deshumanización del arte», en Obras completas, tomo III (1917-1928), Madrid, Revista de Occidente, 1966, págs. 353-386.

Pittarello, Elide, «Ramón Gaya, el pensamiento de la pintura», Artes del ensayo, n. ${ }^{\circ}$ 2, 2018, págs. 5-37.

Schelling, F.W.J., Investigaciones filosóficas sobre la esencia de la libertad humana $y$ los objetos con ella relacionados, trad. de Helena Cortés y Arturo Leyte, Barcelona, Anthropos, 1989.

Sontag, Susan, «Against interpretation», en Against Interpretation and Other Essays, Nueva York, Farrar, Straus \& Giroux, 1982, págs. 5-14.

Spinoza, Baruch, Ética demostrada según el orden geométrico, trad. de Atilano Domínguez, Madrid, Trotta, 2000.

Trapiello, Andrés, «Solo pero no de espaldas (Ramón Gaya y las ciudades)», en VV.AA, Ramón Gaya. El pintor y las ciudades, catálogo de la exposición en el IVAM, 2000, págs. 11-27.

Zambrano, María, Algunos lugares de la pintura, recopilación de Amalia Iglesias Serna, Madrid, Espasa-Calpe, 1989.

Žižek, Slavoj, Interrogating the Real, Londres-Nueva York, Bloomsbury, 2005.

Žižek, Slavoj, The Parallax View, Londres, Verso, 2006.

Žižek, Slavoj, Less Than Nothing. Hegel and the Shadow of Dialectic Materialism, Londres, Verso, 2012.

Žižek, Slavoj, «Ontological Incompleteness in Painting, Literature and Quantum Physics», videoconferencia para la European Graduate School, 2012b. Disponible online: https://www.youtube.com/watch?v=ddctYDCTIIA.

Žižek, Slavoj, Sex and the Failed Absolute, Londres-Nueva York, Bloomsbury, 2020. 